\title{
ESTIMATIVA DA EVAPOTRANSPIRAÇÃO POTENCIAL EM BAGÉ-RS PARA APLICAÇÃO NO ÍNDICE PADRONIZADO PRECIPITAÇÃO- EVAPOTRANSPITAÇÃO
}

\author{
Guilherme Goergen¹, Jônatan Dupont Tatsch², Marcelo Romero de Moraes ${ }^{1}$ \\ ${ }^{1}$ Universidade Federal do Pampa (UNIPAMPA), Bagé, RS, Brasil \\ ${ }^{2}$ Universidade Federal de Santa Maria (UFSM), Santa Maria, RS, Brasil
}

\begin{abstract}
The aim of this study was to evaluate the best method for estimating potential evapotranspiration for the region of Bagé-RS, for its application in standardized precipitation evapotranspiration index (SPEI). Among the methods evaluated, the Penman-Montheith (ET0pen) presented the best estimates compared to measured potential evaporation. The use of ETOpen on index calculation SPEI identified drought periods consistent with those reported in the media.
\end{abstract}

\section{INTRODUÇÃO}

A região de Bagé, sudoeste do RS, é climatologicamente caracterizada por índices pluviométricos anuais relativamente baixos em relação à média da precipitação anual do estado. A precipitação total mensal é regularmente distribuída durante o ano, mas a ocorrência de secas e chuvas intensas é recorrente; acarretando o racionamento de água prolongado à população (p.ex.: junho a setembro de 2009, dezembro de 2005 a junho de 2007 e dezembro de 2010 a janeiro de 2011) e o alagamento da cidade (novembro de 2009), respectivamente. Fica, portanto, evidente a necessidade de se estabelecer uma métrica para quantificação e o monitoramento desses períodos de estiagem, diante das projeções de intensificação dos eventos extremos climáticos pelo Painel Intergovernamental de Mudanças Climáticas (IPCC). O objetivo desse artigo foi avaliar o melhor método para estimativa da evapotranspiração potencial, para região de Bagé-RS, para sua aplicação no índice padronizado precipitação-evapotranspitação (SPEI).

\section{MATERIAL E MÉTODOS}

Os dados do Evaporímetro de Piche (disponíveis de 2002 a 2012 na estação meteorológica convencional - EMC - de Bagé-RS) fornecem uma medida da evaporação potencial (ET0) do ambiente e foram usados para definição do melhor método de estimativa da evapotranspiração potencial. Os métodos analisados foram os de Thornthwaite (ET0tho), Hagreaves (ETOhar) e Penman-Motheith (ET0pen). Após a definição da melhor estimativa da ET0, determinou-se a ET0 para o período de 1961 a 2012 usando os dados meteorológicos (médias mensais de número de horas de brilho solar, velocidade do vento, umidade relativa do ar, temperatura máxima e mínima do ar) da EMC do INMET em BagéRS (coordenadas $31.3478^{\circ} \mathrm{S}, 54.0133^{\circ} \mathrm{O}$, a $230 \mathrm{~m}$ de altitude). A melhor estimativa de ET0 total mensal foi usada no cálculo do SPEI (Vicente-Serrano et al. 2009) que requer também dados de precipitação total mensal.

\section{RESULTADOS E DISCUSSÃO}

Na comparação das estimativas dos totais mensais de ET0 dos três métodos com a evaporação potencial medida (evap) observou-se uma subestimativa sistemática da ET0thor $(\sim 40 \%)$ mais evidenciada entre os meses de junho a outubro (Fig. 1a), resultando em menor 
correlação $\left(\mathrm{R}^{2}=0,63\right)$ em relação aos outros métodos. A ET0har tende a subestimar a evap quando esta diminui $(\sim 10 \%$, Fig. $1 b)$, apesar da maior correlação $\left(R^{2}=0,82\right)$, mostrando maiores discrepâncias nos meses de março a setembro (Fig. 1a). A ET0pen usa uma multiplicidade maior de dados meteorológicos de entrada e, mostrou melhores resultados nessa comparação: subestimativa sistemática da ordem de $1 \%$ (coeficiente angular de 0,99 ) e a maior correlação com a evap $\left(\mathrm{R}^{2}=0,88\right)$.

O SPEI resultante para escala de tempo de 12 meses usando a ET0pen (Fig. 2a) identificou as secas mais severas em 1972-1973 e 1988-1989 e, as mais longas em 19751977 e 2005-2007, coerente com as datas reportadas na mídia estadual. Uma das vantagens do SPEI é que este índice pode ser determinado para diversas escalas de tempo. A Fig. $2 b$ mostra a variação temporal do SPEI para escala de tempo de 1 a 12 meses (eixo y).

(a)

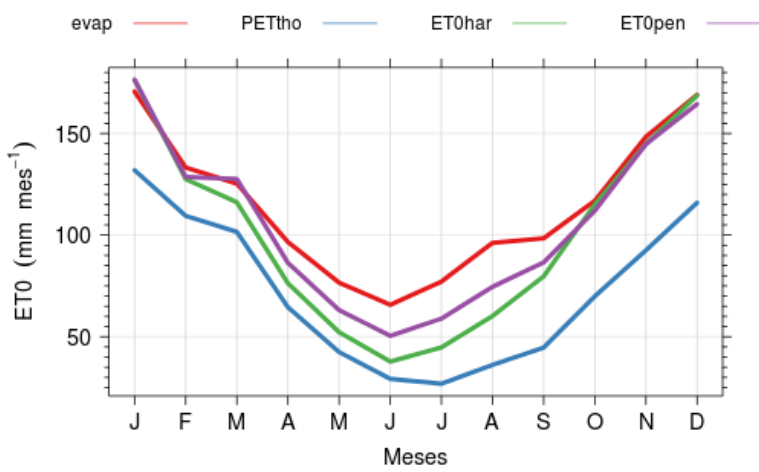

(b)

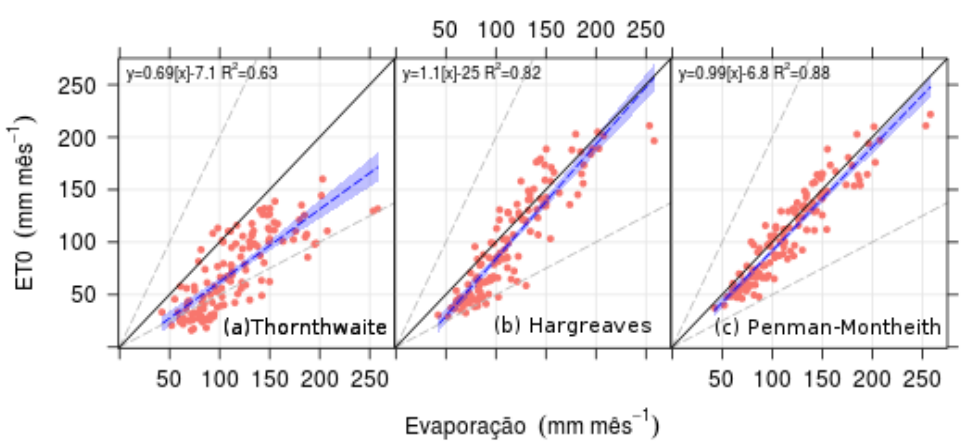

Figura 1 (a) Comparação do ciclo anual médio da evaporação total mensal do Evaporímetro de Piche (evap) com a Evapotranspiração potencial estimada pelos métodos de Thornthwaite (PETtho), Hagreaves (ET0har) e Penman-Motheith (ET0pen) com dados de Bagé-RS (INMET). (b) Diagramas de dispersão entre a evaporação total mensal estimada pelos mesmos 3 métodos (eixo y) e a Evaporação do Evaporímetro de Piche.

Para escalas de tempo menores, as séries de secas mostram uma alta frequência de períodos secos e úmidos de curta duração. Em oposição, para escalas maiores os períodos de seca são de duração maior e frequência menor. Esse padrão evidencia o aspecto multiescalar do fenômeno seca que se define em diferentes tipos (e.g.: agrícola, meteorológica e hidrológica). 
(a)

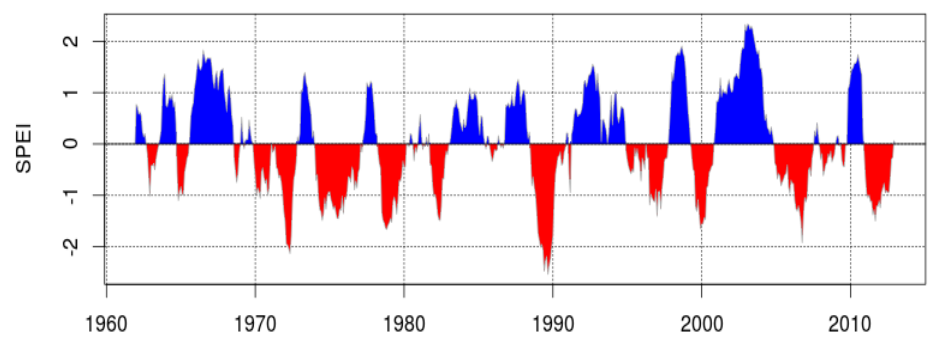

(b)

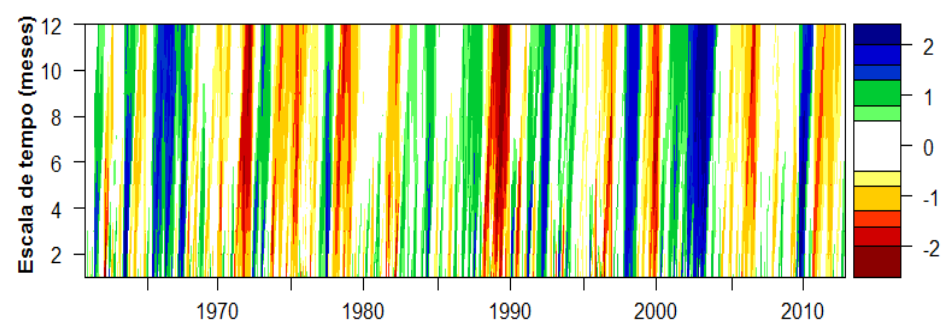

Figura 2 (a) Índice Padronizado de Precipitação-Evapotranspiração (SPEI) para escala de tempo de 12 meses usando a evapotranspiração estimada pela equação de Penman-Montheith (b) Variação temporal do SPEI determinado para as escalas de tempo de 1 a 12 meses.

\section{CONCLUSÕES}

O método que produz melhores estimativas da evaporação potencial na região de Bagé é o de Penman-Montheith, seguido do método de Hargreaves e de Thorntwaite. O uso da ET0pen no cálculo do índice SPEI permitiu identificar períodos de seca compatíveis com os reportados na mídia. O fato de o SPEI ser multiescalar e considerar a temperatura no seu cálculo evidencia seu potencial de uso para o monitoramento de secas na região e na avaliação de impactos futuros decorrentes do aumento da temperatura global (aumento da ET0) e da intensificação dos eventos extremos de precipitação.

\section{REFERÊNCIAS BIBLIOGRÁFICAS}

VICENTE-SERRANO, S.M., BEGUERIA, S, LÓPES-MORENO, J.I. 2009. A Multiscalar Drought Index Sensitive to Global Warming: The Standardized Precipitation Evapotranspiration, Journal of Climate, DOI: 10.1175/2009JCLI2909.1. 